\title{
Jogo de Realidade Aumentada para Auxiliar no Aprendizado Infantil
}

\author{
Beatriz Maia de Oliveira, Ezequiel Roberto Zorzal \\ Instituto de Ciência e Tecnologia, São José dos Campos, Brasil - Universidade Federal \\ de São Paulo (UNIFESP) \\ Rua Talim, 330, 12231-280 - São José dos Campos - SP - Brasil \\ beatriz.maia.o@gmail.com, ezorzal@unifesp.br
}

\begin{abstract}
This paper presents an Augmented Reality game in which the player through the guidance of the marker moves a ball, passing over all the letters in a certain order, in order to form the right word. The game was written in $C$ language, with the help of OpenGL and ARToolKit, using Visual Studio for deployment.
\end{abstract}

Resumo. Este artigo apresenta um jogo de Realidade Aumentada, no qual o jogador através da orientação do marcador movimenta uma esfera, passando em cima de todas as letras em uma determinada ordem, com o intuito de formar a palavra certa. O jogo foi escrito em linguagem $C$, com o auxilio do OpenGL e ARToolKit, utilizando o Visual Studio para implementação.

\section{Introdução}

Com a modernização, os computadores estão mais presentes no dia-a-dia da sociedade. Cada vez mais escolas estão adotando-os para auxiliar no aprendizado e com isso tornase necessário refletir como serão utilizados no processo de ensino-aprendizagem [Moratori 2012].

Há muito tempo os jogos vem prendendo a atenção tanto dos adultos como das crianças. Ao analisar a história da educação é possível perceber que a aprendizagem por meio de jogos e brincadeiras foi incentivada por inúmeros teóricos que desde os tempos da Grécia antiga já ressaltavam sobre a importância da atividade lúdica no processo de formação da criança [Soares 2013]. Então, vários jogos educativos surgiram e foram adotados por escolas para complementar o aprendizado em diversas matérias, como por exemplo, língua portuguesa, matemática, ciência e línguas estrangeiras. Com isso as crianças aprendiam brincando $\mathrm{e}$ as que apresentavam mais dificuldades para aprendizagem tinham uma nova maneira de aprender. $O$ avanço da tecnologia possibilitou que novas oportunidades surgissem e uma delas foi a criação de jogos em realidade aumentada. Ela apresenta uma forma lúdica e descontraída, o que a torna um excelente instrumento de aprendizado. A realidade aumentada permite uma interação segura e agradável, pelo fato de transportar os elementos virtuais ao mundo real [Azuma 2001]. Pode-se interagir de uma forma mais natural com o objeto virtual, tornando assim a interação mais agradável, atrativa e motivadora. Outra vantagem da realidade aumentada é que podem ser criadas aplicações que necessitem apenas de um computador e webcam, tornando-se assim mais acessíveis as escolas, devido ao baixo custo. 
Neste artigo será apresentado um jogo que tem como objetivo auxiliar no aprendizado das crianças que estão começando a aprender a sequencia das letras e formação das palavras. Com ele também é trabalhada a coordenação motora, principalmente a motricidade fina, que é a execução de movimentos finos com controle e destreza, ou seja, é a capacidade de usar de forma eficiente e precisa pequenos músculos, produzindo assim movimentos delicados e específicos, como por exemplo, escrever, recortar, digitar e costurar [Silva e Costa 2013]. A Seção II apresenta alguns trabalhos relacionados, a Seção III escreve o estudo do caso desenvolvido. Por fim, na Seção IV são apresentadas as conclusões desse trabalho.

\section{Trabalhos relacionados}

Com a realidade aumentada é possível criar jogos educacionais nas mais diversas áreas e para vários públicos. Um dos diferencias, que ela apresenta, é que mesmo usuários com algum tipo de deficiência motora e que não apresentam habilidade para manipular o mouse ou o teclado, conseguem interagir com o jogo por meio da movimentação de arraste de um objeto com as mãos, pés, ou algum dispositivo especifico [Correa et al. 2008].

Um exemplo disso é o jogo Tapamática [Frozi 2009], um jogo matemático no qual o usuário deve responder questões envolvendo as quatro operações básicas da matemática. No início o usuário coloca uma máscara acoplada em um óculos que contém quatro marcadores. $\mathrm{O}$ jogador tem que resolver mentalmente a conta e tapar o marcador que apresenta o resultado certo. Um jogo que pode ser utilizado na musicoterapia é o GenVirtual [Correa et al. 2008], no qual o terapeuta pode realizar o "planejamento motor" de cada individuo. Ele é um jogo musical que possibilita seguir uma sequência de cores e sons emitidos a partir dos objetos virtuais projetados no mundo real. As notas musicais são emitidas uma por vez, e o sistema fica à espera da interação do usuário que deverá obstruir o marcador referente à nota musical emitida. A cada acerto, a sequência ganha um novo item (nota musical), aumentando o desafio de memória e retenção de informação do jogo. Outro jogo interessante na área educacional é o Jogo de Palavras [Zorzal et al. 2008], que tem como objetivo fazer com que o jogador junte as letras para formar palavras e resgatar imagens através da técnica de realidade aumentada. Foram desenvolvidos marcadores com letras em seus interiores, e cadastradas combinações de palavras, formando assim marcadores compostos. Quando o usuário forma uma sequência de letras previamente cadastrada, a ARToolKit [Kato, Billinghurst e Poupyrev 2000] mostra um objeto virtual associado aquela combinação.

\section{Estudo de caso}

O jogo foi criado com realidade aumentada e para a execução do jogo é necessário apenas a utilização de um computador, webcam e teclado. Ao mostrar o marcador para a webcam, aparecerá um plano preto, que será o tabuleiro do jogo. No canto superior esquerdo dele haverá uma frase, na cor vermelha, esta é a dica referente à palavra escolhida pelo sistema. Espalhado pelo tabuleiro haverá as letras, na cor verde, presentes na palavra. Uma esfera na cor amarela aparece parada e centrada no tabuleiro.

Para iniciar o jogo é necessário apertar a letra "i” no teclado, assim a esfera começa a se mover de acordo com a inclinação do marcador. A velocidade da esfera é controlada pelas teclas " $r$ " e "d", para aumentar e diminuir, respectivamente. O objetivo do jogo é fazer com que a criança leia a dica fornecida, analise as letras espalhadas pelo 
tabuleiro e descubra qual é a palavra. Depois disso ela irá mover a esfera por meio do marcador, fazendo-a passar por cima de cada letra na ordem correta. Ao passar em cima da letra certa, esta muda da cor verde para a cor vermelha. Ao fazer a sequência correta, a frase "Venceu!" aparece na tela. A Figura 1 mostra uma sequência de jogadas corretas, formando a palavra mãe.
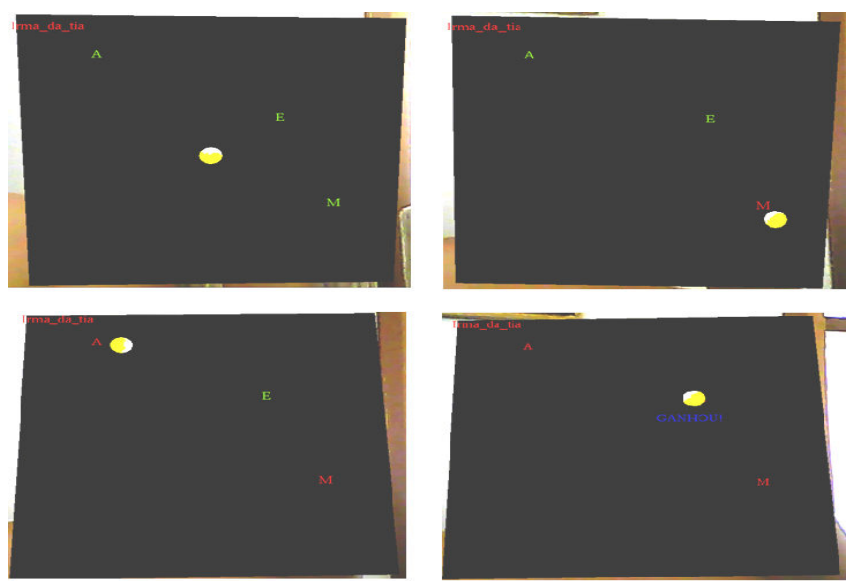

Figura 1 - Sequência de jogadas formando a palavra "MAE"

Caso a esfera passe por cima da letra errada a frase "Perdeu!" que irá aparecer. Se a criança não conseguir descobrir qual é a palavra e deseje ir para outra, basta apertar a letra " $t$ " do teclado, que outra dica e outras letras irão aparecer no tabuleiro aleatoriamente.

Quando estiver jogando e for necessário parar um jogo por uns instantes, basta apertar a tecla "p", que o jogo irá pausar. Com a movimentação do marcador a criança estará treinando a coordenação motora fina, pois é necessário o controle e destreza da mão. Passando a esfera na ordem certa em cima das letras, ela estará aprendendo e fixando a sequência das letras e formação das palavras. O jogo também trabalha a memória, pois a dica é dada sobre a palavra que deve ser formada e a criança deve descobrir qual é esta palavra. Juntamente com o programa do jogo foi criado um arquivo de texto .txt, contendo as palavras e suas respectivas dicas. Com isso, ele também pode ser usado como auxiliar no aprendizado da língua estrangeira, basta criar um arquivo de texto com as palavras e dicas desejadas. Para a elaboração do programa foi utilizado o programa Visual Studio da Microsoft e as bibliotecas ARToolKit e OpenGL [OpenG1 20013]. A linguagem utilizada foi $\mathrm{C}$ e como base foi utilizado o exemplo LoadMultiple.c, do ARToolKit. Para movimentar a esfera foram criadas duas variáveis que verificam continuamente o valor de $\mathrm{X} \mathrm{e} \mathrm{Y} \mathrm{da} \mathrm{matriz} \mathrm{de} \mathrm{rotação} \mathrm{do} \mathrm{eixo} \mathrm{Z.} \mathrm{Quando} \mathrm{o}$ valor de $\mathrm{X}$ for maior que zero e menor que um, ou seja, $0<\mathrm{x}<1$, a esfera se move para um lado. Caso $\mathrm{X}$ seja maior que menos um e menor que zero, ou seja, $-1<\mathrm{x}<0$, ela se moverá na direção contrária. A mesma coisa acontece em relação a variável Y. As

palavras disponíveis e as dicas foram escritas em um documento de texto, com extensão .txt, na primeira linha do documento está escrito a quantidade de palavras presentes no arquivo. A partir da terceira linha são inseridas as palavras e as dicas. Foram criadas funções com o objetivo de executar uma determinada ação quando uma tecla especifica é acionada. 


\section{Conclusões}

Como não é necessária a utilização de nenhum aparelho tecnológico mais complexo, este jogo se torna acessível a maioria das escolas que tem computadores e possuem pelo menos uma webcam. Uma possibilidade interessante para uso de aplicações deste âmbito seria em conjunto com o projeto PROUCA - Programa Um Computador por Aluno. Por iniciativa dos governos Federal, Estaduais e Municipais, o PROUCA, tem como objetivo ser um projeto Educacional utilizando tecnologia, inclusão digital e adensamento da cadeia produtiva comercial no Brasil.

Outros tipos de jogos com realidade aumentada podem ser criados para atuarem nas mais diversas áreas de aprendizado infantil. Como trabalho futuro deve-se fazer um acompanhamento com crianças que estão na fase de alfabetização, utilizando o jogo como um auxiliar na fixação do que foi ensinado em sala de aula. Além disso, uma versão do jogo está sendo desenvolvido para ser usado em dispositivos móveis, tais como smartphones e tablets (utilizando os sensores disponíveis nestes para a interação. Por exemplo, o giroscópio). Ainda, as próximas versões do jogo devem apresentar os objetos tridimensionais relacionados às palavras descobertas ao final das montagens das mesmas. Outros recursos de multimídia tais como a adição de sons, também deverão ser contemplados.

\section{Referências}

Azuma, R. T., Baillot, Y., Behringer, R., Feiner, S., Julier, S., MacIntyre, B. (2001) Recent Advances in Augmented Reality. IEEE Computer Graphics and Applications

Correa, A. G. D. ; Assis, G. A.; Nascimento, M. ; Lopes, R. . GenVirtual: um Jogo Musical para Reabilitação de Indivíduos com Necessidades Especiais. Revista Brasileira de Informação na Educação, v. 16, p. 09-17, 2008.

Frosi, F.; Marson, F. Tapamática: Uma aplicação de Realidade Aumentada com Enfoque Educacional para Estudantes das Séries Iniciais. In: Workshop de Realidade e Virtual e Aumentada, 2009, Santos. $6^{\circ}$ Workshop de Realidade e Virtual e Aumentada, 2009.

Kato, H.; Billinghurst, M.; Poupyrev, I. ARToolKit version 2.33 Manual, Nov. 2000.

Moratori, P. B. Por que utilizar jogos educativos no processo de ensino aprendizagem. Disponível em <http://pt.scribd.com/doc/6770926/Por-Que-Utilizar-JogosEducativos-No-Processo-de-Ensino-Aprendizagem>. Acessado em Fev. de 2012.

OpenGl. Disponível em <http://www.opengl.org/>. Acessado em Out. de 2013.

Silva, G. B. da; Costa, Golemba S. T. Tic e Coordenação Motora. Disponível em $<$ http://www.pucpr.br/eventos/educere/educere2008/anais/pdf/812_587.pdf $>$. Acessado em Out. de 2013.

Soares, Jiane Martins. A Importancia do Lúdico na Alfabetização Infantil. Disponível em

$<$ http://www.planetaeducacao.com.br/portal/imagens/artigos/diario/ARTIGO\%20JIA NE\%20JOGO1.pdf $>$. Acessado em Out. de 2013.

Zorzal, E. R.; Oliveira, M. R.; Silva, L. F.; Cardoso, A.; Kirner, C.; Lamounier Júnior, E. Aplicação de Jogos Educacionais com Realidade Aumentada. RENOTE. Revista Novas Tecnologias na Educação, v. 6, p. 29, 2008. 